\title{
POST-TRAUMATIC STRESS DISORDER OF THE MAIN CHARACTER IN “WILD” MOVIE DIRECTED BY JEAN-MARC VALLEE
}

\author{
Bejo Sutrisno ${ }^{1}$ \\ Sekolah Tinggi Bahasa Asing- IEC Jakarta \\ bejo@stibaiec-jakarta.ac.id \\ Ernissa Yuliana \\ Sekolah Tinggi Bahasa Asing- IEC Jakarta \\ ernisa_yuliana@yahoo.com
}

\begin{abstract}
APA Citation: Sutrisno, B. and Yuliana, E. (2019). Post-Traumatic Stress Disorder of the Main Character in “Wild” Movie Directed by Jean-Marc Vallee . Journal of English Language and literature, 4(2), 74-81. DOI 10.2540/jell.v4i02.83
\end{abstract}

Received: 05-07-2019

Accepted: 15-08-2019

Published: 01-09-2019

\begin{abstract}
The objectives of this research are to describe Post-Traumatic Stress Disorder be shown of the main character and to mention the types of Post-Traumatic Stress Disorder that the main character suffers. In this movie, it shows about Post-Traumatic Stress Disorder Of The Main Character. The movie cuts out a few important people in Cheryl's real life. In the movie, Cheryl has only one sibling, her younger brother Leif. Cheryl and her father grew particularly close during her mother's sickness, but after she passed, Eddie remarried and grew distant. Much of Cheryl's internal monologue during her therapy sessions is made into dialogue with her therapist in the movie. In this movie also explains how to eliminate trauma, by climbing many obstacles by oneself, through many obstacles, so Cheryl feels very grateful for the present life and he realizes that what he does in front must he face, she can not escape from the problem is, because it is history and the future is a mystery that must be dealt with better.
\end{abstract}

Keywords: Post-Traumatic Stress Disorder, main character, qualitative

\section{INTRODUCTION}

As one of genres of literature movie is accepted broadly around the world. According to Monaco (2000) that "Movies are now an integral part of a new, encompassing art, technology, and industry for which we do not yet have a name, except perhaps multimedia. Movie also has values that people can enjoy and take a lot of message". The statement above means movie is an integral part of the art, technology and also has the value of the messages to the audience. Moreover, movie is produced with footage of people and object with camera or by animation. The main point of movie focuses on character that can conveys idea and concept of story fill with the

\footnotetext{
${ }^{1}$ Corresponding author
}

expression of character, then it is influencing audience to feel and receive particular messages.

The character is important element of a movie. A movie will be more interesting if the character is a famous actor or actress. That is why the writer to interested in analyzing the psyche of the character in this movie. Understanding post-traumatic stress disorder of the character in this movie will provide understanding to many other things too.

Main character is the most important people in a movie, television program or a stage show who have the most important part in the story and does the most support the plot. Main 
character in a story is generally as the protagonist, the character who opposes him or her is the antagonist, the character that the reader or audience empathizes with. One interesting topic that related to character is psychological background of the character. There are some mental disorder diseases that can be seen in some movies. One of them is Post Traumatic-Stress Disorder.

Ekkehard and Sieglinde (2005:80) stated that "Post-traumatic stress disorder leads to active resistance to remembering thoughts, images, and memories associated with a trauma". It means that post-traumatic stress disorder is the bad memories or have ever experienced in a way flashback.

The writer chooses the Wild movie because this movie is inspiring the writer about the struggles of life left by a mother and a divorce with her husband. After her mother left and divorced her husband, she was addicted to sex and drugs. To make amends, the main character doing the hike to the Pacific Crest Trail about 1000 miles even though the main characters do not have the experience hike. Cheryl is the main character in the Wild movie.

This study focuses on how post-traumatic stress disorder is shown in the Wild movie, types post-traumatic stress disorder of the main character in the movie, and also the moral message from the Wild Movie Directed by Jean Marc-Vallee.

\section{LITERATURE REVIEW}

\section{Post-Traumatic Stress Disorder}

Ekkehard and Sieglinde (2005:80) stated that "Post-traumatic stress disorder leads to active resistance to remembering thoughts, images, and memories associated with a trauma". It means that post-traumatic stress disorder is the bad memories or have ever experienced in a way flashback.

Moreover, Diane(2009:3) described "posttraumatic stress disorder is apt to develop after and individual has directly experienced, witnessed, or been confronted with one or more traumatic event". From the statement, the writer concludes that the post-traumatic stress disorder is someone who is traumatized by the event or a bad experience he had ever experienced.

Mark Goulston (2008:10) said that "post traumatic-stress disorder is a major, lifealtering disorder that strikes many people who survive traumatic experience". This statement means that PTSD is a part of life disorder that attacks the experience of traumatic.

\section{Type of Post-Traumatic Stress Disorder}

According to Grohol (2015:42) "there are five main types of post traumatic-stress disorder: normal stress response, acute stress disorder, uncomplicated PTSD, comorbid PTSD and complex PTSD".

a. Normal Stress Response

The normal stress response occurs when healthy adults who have been exposed to a single discrete traumatic event in adulthood experience intense bad memories, emotional numbing, feeling of unreality, being cut off from relationships or bodily tension and distress. Based on the statement means the normal stress response when adults who have been exposed to the bad memories of the experience, the feeling of unreality and emotional numbness.

b. Acute Stress Disorder

Acute stress disorder is characterized by panic reactions, mental confusion, dissociation, severe insomnia, suspiciousness, and being unable to manage even basic self care, work, and relationship activities. It means that acute stress disorder characterized by panic, confusion, severe insomnia, excessive suspicion and can't manage themselves.

c. Uncomplicated PTSD

Uncomplicated PTSD involves persistent re-experiencing of the traumatic event, avoidance of stimuli associated with the trauma, emotional numbing, and symptoms of increased arousal. Based on the statement means uncomplicated PTSD is present who people who are continually exposed to traumatic events which is characterized by hyper-alertness and inescapable memories of the event.

d. Comorbid PTSD 
Comorbid PTSD with other psychiatric disorders is actually much more commonly than uncomplicated PTSD. PTSD is usually associated with at least one other major psychiatric disorder such as depression, alcohol or substance abuse, panic disorder. It means that comorbid PTSD is usually one other mental disorders such as depression, alcohol or substance abuse, and depression.

e. Complex PTSD

Complex PTSD (sometimes called "Disorder of Extreme Stress") is found among individuals who have been exposed to prolonged traumatic circumstances, especially during childhood, such as childhood sexual abuse. Based on the statement above complex PTSD is characterized by people who have been exposed to prolonged trauma such as childhood sexual abuse.

Complex PTSD is another highly common type of this disorder, as it occurs in people who have been exposed to traumatic experiences over a longer period of time. It means that complex PTSD occurs in people who have experience for a long period of time.

\section{Anxiety Disorders}

Anxiety disorder is a chronic condition characterized by an excessive and persistent sense of apprehension, with physical symptoms such as sweating, palpitations, and feelings of stress. These are the definition of anxiety disorders by several experts.

Pedrick and Bruce (2012:14) stated that "anxiety is what occurs when the brain's fightor-fight mechanism becomes mistakenly associated in our minds with objects, places, people, situations, or ideas that we don't normally think of as very threatening". The statement above means the anxiety is anxiety that occurs when the brain mechanism mistaken in thinking that very threatening.

Robert (1992:12) described that "anxiety is a widely used concept within the psychological literature yet is often used uncritically and to reflect diverse meanings". This statement means that anxiety is a concept widely used in psychology are still rarely used uncritically and to reflect the variety of meanings.
Mark (2008:28) stated that "Normal stress response this type of PTSD typically starts after a single event for instance, a car accident, a physical attack or natural disaster". It means that normal stress response is usually traumatized by the experience of physical attacks, a car accident or a natural disaster.

From the explanation above, the writer assumes normal stress response is psychological response experienced on encountering a threat that we feel we do not have the resources to deal with example divorce, the death of loved one and car accident.

\section{Type Comorbid PTSD}

Comorbid PTSD is psychiatric disorders are associated with one other major psychiatric disorder such as depression, alcohol or substance abuse. Comorbid PTSD is the most common type of post-traumatic stress disorder.

Edna Foa (2000:38) describes "comorbid PTSD is the most common comorbid include depression, alcohol and drug abuse". Based on Brady statement comorbid PTSD is usually other mental disorder such as depression, alcohol and drug abuse.

From the explanations above, the writer can be concluded that comorbid PTSD is psychiatric disorder associated with alcohol and substance abuse. Comorbid PTSD usually occurs in people who had a mental condition that causes the traumatized.

\section{Character}

Character is a person who responsible for the thoughts and actions within a story. Character is very important because they are the medium through which a reader interacts with a piece of literature. Every character has his or his own personality, which creative author uses to assist in forming the plot of a story or creating the mood. Character is considered of the fundamental components of fiction. Character may be entirely fictional, or they may be based upon real entities, contemporary, or historical. As Eder et al (2010:7) said, "character is as figural sense, or the stamp of personality that which is unique to a human being".

In addition, according to Milhorn (2006:8) said that, "Character are usually human, but can be animals, aliens, robot, or anything you want them to be, characters have name physical 
appearances, and personalities". It means that character is anything presented in literary work of narrative through the action and dialogue.

Roche (2007) described that "in this way, character is seen as a point of communication between the text and the reader: it is a dynamic, active product or production of the reader's interaction with the text." The statement above means the character is a character seen as a point of communication between the reader and the text.

From the explanation above, the writer assumes character is something depend how people see that can be anything which sometimes can be identifying as a player in literary work. Character is an important part in the whole story because if there is no character can't be a story.

\section{Main Character}

The main character is a person who has determination in every part of story. Main character defines as the character that always shows in the story talking to the opposite. These are the definition of main character by several experts.

Long and Schenk (2006:17) described that "main character is introduced, along with his or her nemesis, and the supporting cast". From the statement, the writers conclude that the main character is a character focused on the story.

Milhorn (2006:8) stated that "The main character is the person the audience's view in the story through". It means that the main character is an audience's view that interpreted and developed by people or character, so that it becomes a view in a story enjoyed by audience.

In addition, Gianetti (2008:561) said that "the main character is a far cry from the tired stereo types of most movies of this era". It can be shown Gianetti statement, main character develops by era of movie.
Based on the explanation about the main character above, the writer can conclude that the main character is the center and the point of the story that noticeable to audience from beginning until the ending of the story. Main character is also introduced first in the story and has a big contribution to audience to get a conclusion at the end of the story.

\section{METHOD}

Qualitative method is used to accomplish this analysis. Qualitative research is one of the two major approaches to research methodology in social sciences. According to Bagdon (1972) as a social science qualitative has left its mark conceptually and theoretically on the research.

\section{FINDING AND DISCUSSION}

\section{The Way of Main Character to Solve Her Post-Traumatic Stress Disorder}

\section{Cheryl : But if I can spin the time, I will do it all differently}

This script described that when Cheryl was almost arrived in her destination she realized that she had choose the wrong way to solved her disorder.

From the explanation above, the writer concluded that Cheryl naturally found the way to solve her Post-Traumatic Disorder.

\author{
Cheryl : I realized I didn't have to \\ reach for anything with my \\ bare hands \\ anymore.
}

This script described that when Cheryl realized that she must live forward and should not remember the past, because the life passed is unpredictable and she should not be afraid of what has not happened in the future. By hiked wildly, Cheryl experienced many things that 
life must go on and cannot run away from problems.

\section{The Types of Post-Traumatic Stress}

When Cheryl hike to Pacific Crest Trail passes a lot of snow after that she saw a wolf suddenly Cheryl remember about thought of her mother was ill before died.

Cheryl : Come back! Come back. Come back!

This script described that when Cheryl was a hike to the Pacific Crest Trail passes a lot of snow there she saw a wolf suddenly she shouted "Come back!" after shouted she remember about thought the death of her mother.

From the explanation above, the writer concluded that post-traumatic stress disorder related when Cheryl shouted "Comeback!" after that she shouted she remember about thought the death of her mother. It described about Comorbid PTSD.

\section{DISCUSSION}

\section{Analysis of The Story}

Post-traumatic Stress Disorder is the most important and interesting thing in Wild movie because many scenes of post-traumatic stress disorder that faced by main character. This movie presents the biography drama. In some scenes, post-traumatic stress disorder appears of Cheryl as main character.

\section{Analysis of Post-Traumatic Stress Disorder of Main Character}

In this scene, the writer showed post-traumatic stress disorder shown in the Wild movie. According to Ekkehard and Sieglinde stated that Post-traumatic stress disorder leads to active resistance to remembering thoughts, images, and memories associated with a trauma. There are some data that support the analysis.

\section{Remember about thought \\ a. Thought when Cheryl was played with her mother}

In this scene, writer explained that Cheryl had post-traumatic stress-disorder when she is listening to a song in the car, her flashback as a child was played with her mother.

$$
\begin{array}{ll}
\text { Man } & \text { : So where are you going? } \\
\text { Cheryl } & \text { : I'm hiking the Pacific Crest } \\
& \text { Trail. It goes from the Mexican } \\
& \text { border up to Canada. }
\end{array}
$$

I'll be walking for the next three months

$\begin{array}{ll}\text { Man } & \text { : Wow } \\ \text { Cheryl } & \text { : Up to Ashland } \\ \text { Man } & \text { : You do a lot of hiking? } \\ \text { Cheryl } & \text { : Well, I mean. I'm not }\end{array}$ obsessive, but this is quite a stretch, even for me.

Man : I guess we're gonna be the last human contact you have for a while?

Cheryl : That's true

In the scene, Cheryl met with the couples and she was invited to ride his car. In the car, Cheryl had a conversation with the couple. Cheryl tells them that she wants to hike the Pacific Crest Trail. Cheryl will be walk for the next three months. Shortly afterwards, the man put the songs in the car suddenly Cheryl flashback her mother when she was playing with her mother in childhood.

From the picture above post-traumatic stress disorder be shown when "Cheryl was listening a song in the car suddenly her flashback as a child was playing with her mother". Because she has experienced remember about thought in childhood with her mother.

\section{b. Thought when her mother was ill before died}

When Cheryl hike to Pacific Crest Trail passes a lot of snow after that she saw a wolf suddenly Cheryl remember about thought of her mother was ill before died.

\section{Cheryl : Come back! Come back. Come back!}

This script described that when Cheryl was a hike to the Pacific Crest Trail passes a lot of 
snow there she saw a wolf suddenly she shouted "Come back!" after shouted she remember about thought the death of her mother.

From the explanation above, the writer concluded that post-traumatic stress disorder related when Cheryl shouted "Comeback!" after that she shouted she remember about thought the death of her mother.

\section{Analysis of Type Comorbid PTSD of Main Character}

Brady describes comorbid PTSD is the most common comorbid include depression, alcohol and drug abuse. Here are some seems that the character has experienced:

\section{a. Substance abuse}

In this scene, writer explained that Cheryl had type comorbid PTSD when Cheryl used of substance abuse after being left by her mother's death and divorced with Paul.

After her mother death and divorced with Paul, Cheryl stressed that she uses substance abuse. The writer concluded Cheryl ever used a substance abuse because of stress was by her mother's death and divorced with Paul.

\section{b. Drug}

In this sript, writer explained that Cheryl had type comorbid PTSD when Cheryl ever used drug. drug?

Aimee : Yeah, like everyone is with

Cheryl : I'm an exprementalist. I'm the girl who says yes instead of no.

Based on dialogue above, the writer claimed that there was a situation Cheryl talked to girl about she had used drug by saying "I'm the girl who says yes instead of no". Based on the statement Cheryl ever used drugs when she suffered a stressed left by the death of her mother and divorced with Paul.

\section{b. Remember about images}

\section{Images about tattoo}

In the bathroom, when Cheryl in the shower she saw pictures of tattoo dig horse on her arm suddenly she remember about the image on her arm.

\section{Cheryl : Baby, baby, be my friend}

This script describes that when Cheryl in the shower she saw pictures of tattoo dig horse on her arm and she says "Baby, baby, be my friend" Shortly afterwards she remember when she put these tattoos with Paul before she was divorced with Paul.

From the statement above, the writer concluded Cheryl remembered before divorced with Paul she put these tattoos that they will do something that bounded together. Of scene post-traumatic stress disorder appeared above by said "Baby, baby, be my friend"

\section{Analysis of Type Normal Stress Response of Main Character}

Mark stated that Normal stress response this type of PTSD typically starts after a single event for instance, a car accident, a physical attack or natural disaster. Here are some seems that the character has experienced:

\section{a. Bad memories}

In this scene, writer explained that Cheryl had type normal stress response when Cheryl put tattoo with Paul before she divorced.

Tattooist : So, what does this tattoo mean to you guys, anyways?

Paul : Well, we both just really dig horses.

Cheryl : We're getting divorced today. And we thought we should do something that bounded us together.

Tattooist : Oh. Okay

Based on dialogue above, the writer claimed that there was a situation Cheryl talked to the tattooist about of type normal stress response by saying "We're getting 
divorced today. And we thought we should do something that bounded us together". This statement is a bad memories for Cheryl.

\section{b. Emotional Numbing}

Note: "Please ensure that you only use white gas compatible with this stove other fuels may harm the equipment and render it inoperable".

The script above, Cheryl annoyed because she did not bring the white gas compatible with this stove while the books that she read the instructions should use white gas compatible with this stove other fuels may harm the equipment and render it inoperable.

From the explanation above, the writer concluded that emotional numbing when Cheryl says "Shit" because she annoyed did not bring white gas compatible with this stove.

\section{c. Physical Attack}

In this scene, writer explained that Cheryl had type normal stress response when Cheryl does not like to eat the sandwich and Cheryl's father suddenly want to punch Cheryl.

Cheryl sandwich?"

:You want a knuckle

Cheryl's Father : You want a knuckle sandwich?

When Cheryl about 8 years old, Cheryl and his father were having dinner at dining room however Cheryl do not like to eat sandwich and her father annoyed suddenly Cheryl want punched by her father.

From the sript above, the writer concluded that psychical attack when Cheryl says "you want a knuckle sandwich" and her father suddenly want to punch Cheryl.

\section{REFERENCES}

Bruce M. Hyuman \& Pedrick. 2012. Anxiety Disorders. U.S.A: A division of Lerner Publishing Company, Inc

England, Diane. 2009. The Post-Traumatic Stress Disorder Relationship. United State of America: W Media Inc

\section{CONCLUSION}

This part explain that the writer used some books, internet and articles, the writer makes the conclusion and suggestion to respond the problem that have been raised before, psychological conflict is the struggle of one person against himself, his conscience, his guilty or simply trying to decide what is going to do. The writer sees that Cheryl in PostTraumatic Stress Disorder of The Main Character in "Wild" Movie Directed By JeanMarc Vallee shares most of the story and experiences in this movie.

Based on Jean-Marc Vallee, in the movie, it shows about Post-Traumatic Stress Disorder of The Main Character, Cheryl is the main character who has Post-Traumatic Disorder and she wants to treat her disorder because she feels tortured. At the beginning Cheryl, a woman who is trying to rebuild their lives shattered and has severe problems with her mother death. Although as a child of a broken home, Cheryl and little brother is a child who was never a lack of affection. Despite the hard life, her mother always taught to enjoy life. Cheryl Mom's has a tough stance despite having to face a difficult life. Abusive husband and drunk causing her divorce and then have to be poor and still support her children. At age 45 years, her mother death cause of cancer.

Destruction in her life led her to use drugs and had a wild life. Although, she already has a caring husband two children's, Cheryl behavior did not stop and take her to divorce. Do not want to keep on dumps, Cheryl take a decision reckless to try to do the hike about 1.000 miles in Pacific Crest Trail. Actually, Cheryl never had experience in hike. She calls her newly exhusband Paul before she sets off on her journey.

Eder, Jens et al. 2010. Characters in fictional worlds: Understanding Imaginary beings in Literature, Film, and Other Media. Germany: Hubert \& Co.

Gianetti, Louis. 2008. Understanding Movies Eleventh Edition. USA: Pearson education Inc. 
John M. Grohol, Psy.D. 2015. Type of PostTraumatic Stress Disorder. http://psychcentral.com

Long, Ben and Sonya Schenk. 2006. The Digital Film Making Handbook. USA: Charles River Media

Mark, Goulston. 2008. Post-Traumatic Stress Disorder. Canada: Wiley Publishing Inc

Milhorn, H. Thomas. 2006. Writing Genre Fiction: A Guide To The Craft. Florida: Universal Publisher
Monaco, James. 2000. How to Read a Film. New York: Oxford University Press

Robert J. Edelmann . 1992. Anxiety Theory, Research and Intervention in Clinical and Health Psychology.

Roche, Isabel.2007. Character and Meaning in the Novel of Victor Hugo. USA: Purdue University Press 